\title{
Aircraft accident in Brazil: Boeing vs. Legacy?
}

\author{
I. M. Almeida ${ }^{1}$, A. I. B. B. Paraguay ${ }^{2}$ \& M. L. A. B. Reichmann ${ }^{3}$ \\ ${ }^{I}$ Public Health Department, Faculty of Medicine, \\ State University of São Paulo (FMB-UNESP), Brazil \\ ${ }^{2}$ Environmental Health Department, Faculty of Public Health, \\ University of São Paulo (FSP-USP), Brazil \\ ${ }^{3}$ Pasteur Institute, State Health Department of São Paulo, Brazil
}

\begin{abstract}
Air accidents represent a small proportion of the flights registered worldwide. Airplane collisions in the air are rare. In September of 2006, a Boeing 737-800 collided in midair with a Legacy Jet. It was the largest accident registered in the history of Brazilian aviation until that time. The present study explores aspects of press coverage of the accident. Data and information reported in the media about the accident from September 2006 to August 2007 were collected and discussed. Media coverage called attention to two unusual aspects: politicisation of the discussion, culminating in the opening of congressional inquiries, and equally the concomitance of police investigations interfering in the work of agencies responsible for the official accident investigation. Emphasis on assigning guilt and establishing penalties may close the windows of opportunity an accident had opened for discussions on the improvement of air safety. In Brazil, political imperatives and organizational pressures have interfered and the possibilities of organizational learning from the accident have been drastically curtailed.

Keywords: air accident, investigation of accidents, conception of accidents, fatal accidents, causality, flight safety, safety system, air safety, Boeing, Legacy.
\end{abstract}

\section{Introduction}

On the 29th of September 2006, on the route between Brasilia, DF and Manaus, the state capital of Amazonas, the worst accident in Brazilian aviation history occurred: a mid-air collision between two airplanes, a Boeing 737-800 and a Legacy executive jet. The accident killed 148 passengers and six Boeing crewmembers. 
Brazil has a total fleet of 10,000 aircraft, of which 200 comprise the commercial fleet. The country depends on 66 airports administered by Infraero and, in 2004, had an annual movement of 2 million takeoffs and landings transporting 82 million passengers. In the year 2000, the index of accidents in the country was 0.4 per million takeoffs.

In the 1970s Brazil adopted an airspace control system that integrates the civilian and military areas. The Ministry of Defence sits atop the system's hierarchy, and is subdivided into the Air Force Command and the National Civil Aviation Agency (ANAC). The Department of Airspace Control (DECEA) is subordinate to the Air Force Command and, in its structure, includes the Center for Integrated Air Defence and Air Traffic Control (CINDACTA). In 2007, the national territory was controlled by four CINDACTAs, with CINDACTA 1, headquartered in Brasilia, covering an area of approximately 1,500,000 $\mathrm{Km}^{2}$.

The System for Investigation and Prevention of Air Accidents (SIPAER) links the civilian and military sectors and includes the Center for Investigation and Prevention of Air Accidents (CENIPA).

In turn, ANAC is the agency that regulates airport infrastructure for civilian aviation and other technical aspects, including aircraft and crews. INFRAERO, responsible for airport administration, is one of ANAC's bodies.

\subsection{The three dimensions of accidents}

Accidents are multi-dimensional phenomena, which receive high visibility when they are of major proportions as in the case of air disasters, which cause high numbers of victims. Three dimensions tend to stand out immediately after accidents: the dramatic, the legal-political and the socio-technical.

The dramatic dimension emphasizes the human costs suffered by the victims, their families and close friends, including work colleagues. The media show images of accident scenes, victim rescue, family reaction, and other images that show the human consequences, thus exploiting the emotions of viewers and readers.

The legal-political dimension initially deals with the impact of material and financial costs. Notably, accusations arise to identify those supposedly responsible and propose legal action in order to compensate victims' relatives by means of fines and direct payments. Since the accident in Bhopal, discussion of these aspects has grown, involving environmental aspects and inputs from government and other agencies that participate in response to emergencies.

More recently the legal-political dimension has also allowed us to zoom in on the political consequences of disasters, even when the official investigation does not find "causes" of a political or even conspiratorial nature. For example, "when TWA Flight 800 blew up near Long Island [...] Mr. Clinton ordered several changes in airport security procedures, including identification checks and queries about luggage. He appointed an acorn mission headed by Vice President Al Gore to suggest more improvements. Within a month of the panel's initial report, most of its recommendations were implemented by Congress" (Sullum [10]). 
According to Dekker [4] some "recent cases where pilot and air-traffic controllers were held accountable by courts and other parties ignorant of the real trade-offs and dilemmas that make up actual operational work" can be seen as examples of situations where "accounting is perceived as illegitimate, for example, intrusive, insulting, or ignorant of real work [...]".

Lastly, the socio-technical dimension explores causal processes of accidents. The initial emphasis is based on the active errors or facts occurring in the period immediately preceding the accident.

In recent decades there has been increasing criticism of accident investigation practices that explain these events only as the product of human failure. Accidents that occur within complex modern technologies such as commercial aviation have been denominated organizational accidents (Reason [9]). Progress on safety has become synonymous with taking a systemic perspective and moving beyond blame (Dekker [4]).

Specifically about air accidents, Reason [9] states:

"It should be apparent by now that a [...] person - centred investigation in the case of the jumbo jet crash would have little or no chance of improving the system's safety. So long as people continue to be employed in modern technological systems, there will always be active failures - but very few of them will have negative consequences because most will be caught by the defences. We cannot change the human condition, but we can change the conditions under which people work".

In Brazil, CENIPA divides its air accident analyses into three categories of factors: human, material, and operational. Although investigation is presented as multicausal, it separates influence from isolated factors in a way that failures classified as operational can also be interpreted as products of human error and not as signs of system failure (Cardoso and Cukierman [3]). Even so, it is notable that the recognition of socio-technical approaches is ascendant.

In the periods following major accidents these three dimensions are normally aggregated. Hypertrophy is often found in the search for the guilty and in the idea of assigning responsibility. Despite the prevalence of the person-centred paradigm, the concept of organizational learning is gaining acceptance.

\subsection{Just culture versus blame-free culture}

One of the current debates in accident prevention involves on one side those defending what is called just culture and on the other side those defending a blame-free culture.

Members of these movements criticize the traditional approach or paradigm of safety which concludes accident analyses: a) attributing the occurrence to human errors or failures by the operators themselves and b) understanding the origins of these failures as being linked to conscious actions or choices made by these operators, or their psychological characteristics in situations where it was prescribed to act in a proper and safe way, as dictated by safety guidelines.

Studying the error production process shows that error has multiple sources and that only some of these sources lie in the individual characteristics of a 
person (Leplat [7]). Even so: “[...] Approximately $88 \%$ of serious accidents in general aviation have been attributed recently to human error" (Amalberti [2]).

In these statistics the term "human error" applies only to pilot errors. To define human error is not easy and, thus, these statistics should [...] be discussed more critically and for further analysis (Amalberti [2]).

Westrum (apud Reason [9]) has distinguished three types of organizational cultures according to the way they deal with safety-related information: pathological, bureaucratic and generative. In pathological culture failure is punished or concealed. This practice impedes the building of a culture of safety, and in contrast to what its supporters imagine, does not help attempts to prevent accidents in complex socio-technical systems.

However, Reason does not defend a blame-free culture. According to him, "A blanket amnesty on all unsafe acts would lack credibility in the eyes of the workforce. [...] What is needed is a just culture, an atmosphere of trust in which people are encouraged, even rewarded, for providing essential safety-related information - but in which they are also clear about where the line must be drawn between acceptable and unacceptable behaviour." (Reason [9])

To build such an atmosphere would be a way of stimulating progress in the direction of a generative culture. Reason [9] recognises the difficulties associated with this process: "The key questions relate to intention. If both the actions and the consequences were intended, then we are likely to be in the realm of criminal behaviour and that is probably beyond the scope of the organization to deal with internally." He proposes "a decision tree for determining the culpability of unsafe acts".

In his approach, Dekker defends the possibility of constructing a blame-free culture.

"Everybody loses when human error gets criminalized: Upon the threat of criminal charges operators stop sending in safety-related information; incident reports grind to a halt. Criminal charges against individual operators also polarise industrial relations [...]" (Dekker [4])

"A lot of lip service is paid to the myth of command residing in the cockpit, to the fantasy of captain as ultimate decision-maker. But today the commander must first consult with the accountant" (Wilkinson 1994, p 87) (apud Dekker [4]).

Dekker's main arguments for his point of view are:

"Error, then, must be understood as the result of constraint that the world imposes on people's goal-directed behaviour. As the local rationality principles dictate, people want to do the right thing, yet features of their work environment limit their authority to act, limit their ability to live up to the responsibility for doing the right thing" (Dekker [4])

"Individual [...] authority is not only restricted because of the large structures" (of which people are only small parts). Authority to assess, decide, and act can be limited simply because of the nature of the situation. When time, information and other resources for making sense of a situation may be lacking or not at hand or ambiguous, there may be all kinds of subtle organizational 
pressures to prefer certain actions over others; and there may be no neutral or additional expertise to drawn on. (Dekker [4])

The objective of this article is to explore aspects of the Brazilian media coverage of the collision in 2006 between a Boeing 737-800 and an Embraer Legacy 600 business jet in an attempt to identify and discuss: a) the most emphasized aspects, b) possible associated reasons; and c) possible consequences for investigation and for the safety field in Brazilian aviation.

\section{Materials and methods}

The materials used in this study were printed and online main journals and news reported between September 2006 and August 2007. The basic description of the accident is based on the National Transportation Safety Board - NTSB Safety Recommendation [6]. News and scientific articles were selected for references to consequences or aspects related to the legal-political dimension of accidents.

\section{Results}

\subsection{The accident}

According to the National Transportation Safety Board - NTSB Safety Recommendation - ([6]) "On September 29, 2006, about 16:57 Brasilia Standard Time, a Boeing 737-800 (PR-GTD) operated by Gol Airlines of Brazil and an Embraer Legacy 600 business jet (N600XL) owned and operated by Excelaire of Long Island, New York, collided in flight over the Amazon jungle approximately 100 nautical miles (nm) southeast of Cachimbo Air Base, Brazil. The Boeing 737 was destroyed by in-flight break-up and impact forces; all 154 occupants were killed. The Embraer Legacy sustained damage to the left wing and left horizontal stabilizer, and the flight crew subsequently performed an emergency landing at Cachimbo Air Base. The two crew members and five passengers were not injured, and there was no further damage to the airplane." The Boeing 737 and the Embraer Legacy were operating by instrumental flight rules (IFR). "Visual meteorological conditions prevailed in the area at the time of the accident."

With the investigation in process, the press noticed that there may have been failures or deficiencies in the radio system at the Integrated Air Defence and Air Traffic Control Centre Cindacta-1, located in Brasília (DF), which could have impeded contact attempts between the Legacy and the flight control centre in Brasília.

More information about the accident background is available in the NTSB Recommendation. Discussing the collision it states:

"Preliminary findings in the ongoing investigation indicate that [...] the collision avoidance system in the Legacy airplane was not functioning at the time of the accident [...]. In addition, CVR data indicate that the flight crew was unaware that the collision avoidance system was not functioning until after the accident”. (NTSB [6]) 
Exploring the possibilities of how this system's design contributed to the collision, the Recommendation continues:

"In the Legacy airplane involved in the accident, the only notification the pilots likely received regarding the loss of TCAS functionality was a small, static text message on the pilots' flight display that read "TCAS OFF" in white lettering. In the event of a TCAS failure, the warning "TCAS FAIL" would be illuminated in amber [...]. Loss of transponder functionality is indicated by a small message on the radio management unit that reads "ATC FAIL" or "STANDBY." In the event of loss of transponder functionality, the "TCAS OFF" or "TCAS FAIL" message will also be displayed [...]. The collision avoidance system does not require pilots to acknowledge or cancel these warnings. National Transportation Safety Board investigators' preliminary survey of a number of transport-category aircraft found that annunciations of TCAS and transponder failure were consistent with those used on the Legacy airplane.

Using only static text messages to indicate a loss of collision avoidance system functionality is not a reliable means to capture pilots' attention [...]. The Safety Board notes that the notifications for other critical aircraft system failures that could result in catastrophic consequences generally use both aural alerts and conspicuous visual alerts [...]. These warnings also require the flight crew to acknowledge that the annunciation has been detected [...] the Safety Board is concerned that pilots may not be quickly alerted or aware that the TCAS and/or transponder are not functioning, leading to their aircraft not being detectable to other TCAS-equipped aircraft and a potential accident $[\ldots]$ " may occur.

At the same time the accident analysis process was conducted by sector technicians, another process started that was marked by governmental action; politicians (deputies and senators); representatives from local police in the accident area and the Federal Police; members of the Prosecution Service and lawyers representing families of victims, pilots, and controllers of the flights involved. There was no lack of statements in the name of organizations representing the parties involved, including unions and aircraft companies.

\subsection{Looking for the guilty and petty politics}

One of the main themes in the press after the accident was looking for persons to blame.

On the night of the accident, one of the main Brazilian newspapers reported that according to the Ministry of Defence the accident could have been caused by lack of attention on the part of one of the airplane crews.

For the next few days, the same type of explanation continued to appear in the news. For example, air controllers from Cindacta-1 were alleged to be in error allowing the Legacy to not change its flight level after passing Brasília city. In turn, the Legacy flight crew were accused of not following the change indicated in their flight plan (Newspaper Folha de São Paulo [5]).

It is important to say that since the first reports of the story were released, those supposedly guilty - pilots and air traffic controllers - were publicly identified. Their names and photographs were widely published. This practice 
contravenes standards adopted by the NTSB in relation to an accident in 2005 whose investigation was published two years later. Commenting on the conclusion of this investigation, Kirby ([8]) reported that: "The NTSB report did not identify the air traffic controller or say whether the person has been disciplined".

The press showed that the crisis in the Brazilian aviation sector had deep roots, pointing out that in the years before the accident, governmental authorities had given incentives for investments in passenger comfort in airports while apparently relegating flight safety to one of its lowest priorities. There were soon accusations of improper diversion of airports renovation funds. Another uncovered aspect was the conflict in relations among different actors with air safety responsibilities.

The news stories released suggest that the good performance of the Brazilian air traffic system was attained by virtue of efforts of its members in a context that includes maintaining older out-of-date technical resources and gradual accumulation of problems that weakened its safety and reliability. This signifies that it maintained "incubated forms of functioning and conditions", which despite not being immediately recognizable in isolation as signs or warnings of immanent danger and not affecting the habitual development of activities, these forms can interact with each other or with a new aspect and then exceed the defence capacities installed in the system, leading to accidents" (Almeida and Jackson Filho [1]).

\subsection{Federal Police in the field}

After the accident the Federal Police quickly opened a police inquiry dedicated to investigating the accident, with the announced aims of exploring the same theme: to identify and punish the person or persons guilty of causing the disaster.

From the very beginning of this inquiry, the American pilots of the Legacy were accused of being negligent and responsible for the accident. At the end of the inquiry, they were formally charged. Also the air traffic controllers who worked at Cindacta-1 were accused of not having followed "the correct flight authorization procedures and for failures in ground-to-air communications laid out in the Aeronautics manual which could have avoided the collision".

\subsection{Political dispute interferes in the development of the investigation}

Soon after the accident, the country's air traffic control system collapsed. Flight delays and cancellations multiplied. Passengers remained for hours, even days, in airport queues. The Ministry of Defence, the Air Force commandant, the National Civil Aviation Authority (ANAC), and the authorities responsible for the airports (Infraero) all entered into open political dispute. Military authority over the country's flight control was questioned with support gaining for its demilitarisation. 
The situation thus acquired the status of the main political problem in the country and the National Congress included it in its daily agenda with accusations against the government and its allies.

At the beginning of 2007, after many discussions parliamentary inquiry commissions (CPI) were set up in both National Congress chambers: one in the Senate and the other in the Chamber of Deputies, both aiming to investigate the crisis in the aeronautical sector.

With the setting up of these two commissions, their members got evidence from the press and the same subjects came back to the fore. In one of his first declarations the president of the Chamber of Deputies Commission declared that the Cindacta-1 air traffic controllers were responsible for the accident and should be penalized.

Another of the commission's goals was to pressure the CENIPA team charged with the official investigation of the accident in order to ensure that the team would make public all the information used in its analysis.

The scene was set: the Legacy pilots and the controllers were quickly invited to give statements to the commissions. Members of one commission confirmed that the Legacy pilots should be given prison sentences.

The facility of media access on the part of victims' families as well as the public effect of the number and duration of flight delays and passengers complaints appear to have influenced this process, which was accelerated in 2007 after a more serious accident at the Congonhas Airport, situated within the urban zone of the city of Sao Paulo, Brazil. In conclusion, the fact that most persons affected by the crisis belonged to the top levels of the Brazilian social pyramid appears to have contributed to the augmented levels of media coverage in the country.

\section{Final comments}

An accident may open up an opportunity for discussions on the improvement of safety. Recent history in Brazil shows that these opportunities are threatened and can be lost when, in the disturbing conditions following air disasters, interests divorced from safety conduct the investigative process immediately after the accident, including and leading to polarised opinions and political conflicts.

In recent years "the approach of aeronautical engineers and aircraft manufacturers to the problem of human error has been to increase automation of flight systems [...] this approach tends to take the human operator out of the manual control loop (Amalberti [2]).

"[...] the role of the pilot has become that of the system manager rather than executive [...] Systematic analysis of accidents in civil aviation show that $80 \%$ of errors are of three types: errors in the representation of system function, errors in parameter selection, and errors in crew coordination. [...]. Thus, due to new technology, the nature of in-flight difficulties has changed" (Amalberti [2]).

In situations such as the functioning of the Legacy jet's collision avoidance system, even when the presentation of vital information was inadequately designed in the official analysis of the accident, the information not detected by 
the crew would be classified as an operational failure committed by the pilot, or in other words, human error. Therefore, the investigation report will not indicate a contributory technical or design failure in the system.

In general, having access to this type of information and press releases, the media tend to transform the person(s) who made the error into the person(s) responsible for the accident. In Brazil, this behaviour has been reinforced by political and police actions, which give resonance to the accusations demanding punishment of the suspects even before the conclusion of investigations led by different commissions. As a consequence, a typical case of organizational accident is presented as a product of errors perceived as being shaped predominantly by psychological factors committed by free agents capable of choosing between safe and unsafe behaviour.

This form of discussing the latest happenings that triggered the accident tends to highlight them as "the causes". This approach does not take into account that, in the majority of cases, these "causes" only prompted the accident in conjunction with other factors present at the time and in the presence of the underlying historically constructed fragility within the system.

Regarding the mentioned accident, the Federal Police and parliamentary inquiry commissions created a threatening climate, which made cooperation from any segment involved in the accident almost impossible. This context prevented any development of systemic thinking in the safety field and tended to reactivate explanations of organizational accidents as events centred only on persons, specifically on pilots and flight controllers.

In the middle of this process the imprisonment of the air traffic controllers involved in the accident who belonged to the armed forces, seems to reinforce the idea that this sector's culture in Brazil might be defined as a pathological one marked by rejecting the concept of "learning from one's mistakes".

Another trait of such context was shown in the replacement of the head of the Aeronautical Accident Prevention and Investigation Centre (CENIPA). His dismissal shattered the international practise of preserving this institution that should benefit from the construction of a climate of confidence and a culture of justice and reporting. Moreover, statements, black box recordings, and other information available to the parliamentary inquiry commissions were made public practically immediately after being submitted.

This scenario seems to confirm that "in aviation [...] culpability is a highly flexible category. Culpability is negotiable, subject to national and professional interpretations, influenced by political imperatives and organizational pressures, and part of personal or institutional histories." (Dekker [4])

The final report of the CENIPA official investigation is due in January 2008 and it is still not possible to discuss the likely impacts it may receive from the events discussed in this text. However, the hope is that its conclusions will reopen the possibility of recovering the effort directed towards the organisational learning process in this sector, thus rejecting the attempts to explain accidents as isolated products of human failures without participation of elements incubated in the history of the systems in question. 


\section{References}

[1] Almeida, I.M.; Jackson Filho, J.M. Acidentes e sua prevenção. Revista Brasileira de Saúde Ocupacional 32(115), pp. 7-18, 2007. (Available in www.fundacentro.gov.br/rbso) (in Portuguese)

[2] Amalberti, R. Safety in flight Operations (Chapter 10). Reliability and Safety in hazardous work Systems, ed. B. Wilpert, T. Qvale, Lawrence Erlbaum Associates Publishers: Hillsdale, pp. 171-194, 1993.

[3] Cardoso, V.A.F.; Cukierman, H.L. A abordagem sociotécnica na investigação e na prevenção de acidentes aéreos: o caso do vôo RG-254. Revista Brasileira de Saúde Ocupacional 32(115), pp. 79-98, 2007. (Available in www.fundacentro.gov.br/rbso) (in Portuguese)

[4] Dekker, W.A.S. Should we hold people Accountable for their mistakes? (Chapter 10) Ten Questions About Human Error. Lawrence Erlbaum Associates, Publishers: London, pp. 193-204, 2005.

[5] Folha de São Paulo (on line). Cotidiano. Cobertura completa do acidente com o vôo 1907. Disponível em <http://www1.folha.uol.com.br/ folha/cotidiano/ult95u126630.shtml.

[6] National Transportation Safety Board (NTSB) Safety Recommendation (A07 35 37). http://www.ntsb.gov/Recs/letters/2007/

[7] Leplat, .J. Event Analysis and Responsibility in Complex Systems (Chapter A.3). After the event. From Accident to Organizational Learning ed. A. Hale, B. Wilpert, M. Freitag, Pergamon: New York, pp. 23-40, 1997.

[8] Kirby, .P Air traffic controller partly to blame for plane crash that killed Zinn, NTSB says. http://www.dailyfreeman.com/site/news.cfm?dept id= 74969\&PAG=461\&BRD=1769\&newsid=19009227.

[9] Reason, J. Managing the Risks of Organizational Accidents. Ashgate: Aldershot, 1997.

[10] Sullum, J. Crash Course in Flight Safety. Washington Times, 21 Nov 1997. http://www.iprr.org/admin/tour.html. 